\title{
Letter to the Editor Regarding the Article on "Turkish Board of Neurological Surgery"
}

\author{
Gokmen KAHILOGULLARI \\ Ankara University Medical School, Department of Neurosurgery, Ankara, Turkey
}

Corresponding author: Gokmen KAHILOGULLARI gokmenkahil@hotmail.com

I have read the article by Bulduk and Yilmaz regarding the Turkish Board of Neurological Surgery (TBN) (1). I want to congratulate the authors for this review article, make some contributions on the foundation and structure of TBN, and provide additional knowledge on the American and European Boards of Neurosurgery. Nevertheless, some very important points were not addressed in this article.

The authors mentioned that TBN was founded as a spontaneous or secondary event after the board formation of other medical specialties in 2005 . However, after acquiring detailed information from senior neurosurgeons, who worked in the foundation of the TBN, I think that the knowledge on the foundation process and dates should be completed by adding historical facts noted below.

The groundwork of the "Turkish Board of Neurosurgery" had already been established in 1994 by Aykut Erbengi, MD, from Hacettepe University, and Ali Savas, MD, PhD, from Ankara University, not in 2005, after the appointment of the Turkish Neurosurgical Society. Both neurosurgeons worked intensively and meticulously with weekly meetings for 6 months, and finally, they wrote the general outline for the rules and regulations of the Turkish Board of Neurosurgery.

This TBN cornerstone involved all functional rules regarding the foundation, regulation acts, election of first committees, main standards of Neurosurgical Departments, and recommendation for academic assignments. As they were preparing these regulations, the structure of the "American Board of Neurosurgery" and "European Board of Neurosurgery" were the main sources, respecting their foundation and compatibilities. This study was published in the "Türk Nöroşirürji Dergisi" (Turkish Journal of Neurosurgery) in 1995 (2) (Figure 1). As a matter of fact, "the Turkish Board of Neurosurgery," which was published in 1995, was "the first board study in medical specialties in Turkey," and most of other medical branches took and accepted it, as a resource, while preparing their boards.

This board study was discussed, voted, and accepted at the General Assembly of the Turkish Neurosurgical Society in 2005,

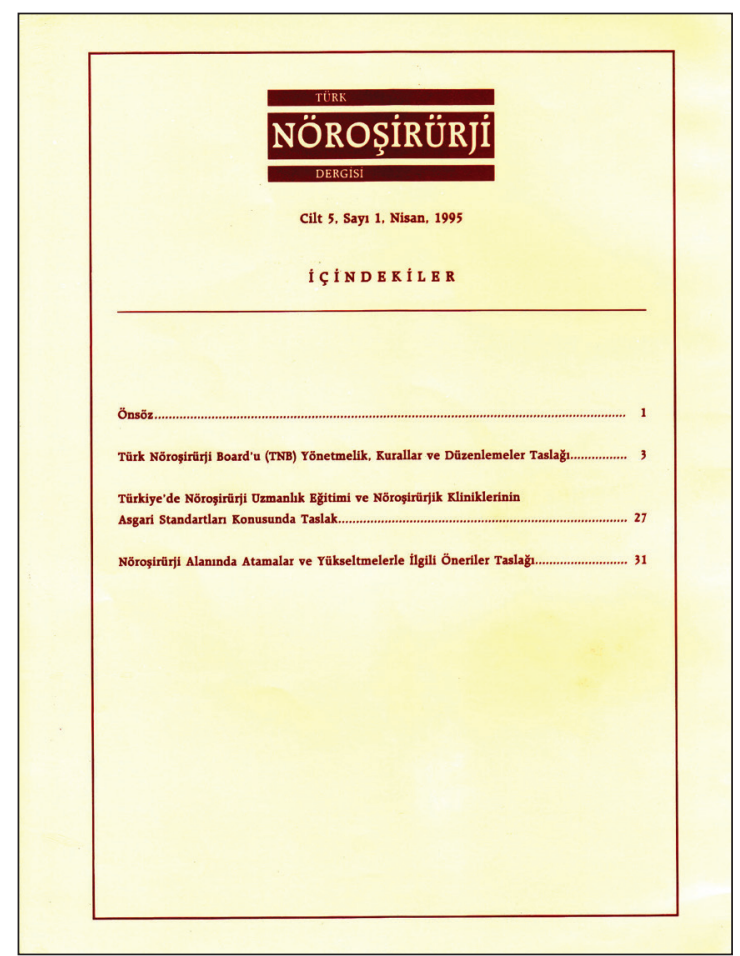

Figure 1: Turkish Journal of Neurosurgery, Vol: 5, Issue: 1, 1995.

and the first officers were elected based on the previously prepared regulations; thus, the TBN was only activated in 2005. However, studies had obviously started years before, and the groundwork had already been completed.

\section{REFERENCES}

1. Bulduk EB, Yilmaz C: Turkish Board of Neurological Surgery. Turk Neurosurg 29: 121-126, 2019

2. Turk Norosirurji Bordu. Turk Norosir Derg (ISSN 1019-5157) 5: 3-36, 1995

Gokmen KAHILOGULLARI (1) : 0000-0001-8137-0510 